\title{
Advance euthanasia directives: a controversial case and its ethical implications
}

\author{
David Gibbes Miller, ${ }^{1}$ Rebecca Dresser, ${ }^{1,2}$ Scott Y H Kim ${ }^{1}$
}

\begin{abstract}
'Department of Bioethics, Clinical Center, National Institutes of Health, Bethesda, Maryland, USA

${ }^{2}$ School of Law, Washington University, Saint Louis, Missouri, USA
\end{abstract}

\section{Correspondence to}

Dr Scott Y H Kim, Department of Bioethics, Clinical Center, National Institutes of Health, Bethesda MD 20892, USA; scott.kim@nih.gov

Received 25 October 2017 Revised 5 January 2018 Accepted 5 February 2018 Published Online First 3 March 2018

- http://dx.doi.org/10.1136/ medethics-2018-104780

- http://dx.doi.org/10.1136/ medethics-2018-104951

Check for updates

To cite: Miller DG, Dresser R, Kim SYH. J Med Ethics 2019;45:84-89.

\section{ABSTRACT}

Authorising euthanasia and assisted suicide with advance euthanasia directives (AEDs) is permitted, yet debated, in the Netherlands. We focus on a recent controversial case in which a Dutch woman with Alzheimer's disease was euthanised based on her AED. A Dutch euthanasia review committee found that the physician performing the euthanasia failed to follow due care requirements for euthanasia and assisted suicide. This case is notable because it is the first case to trigger a criminal investigation since the 2002 Dutch euthanasia law was enacted. Thus far, only brief descriptions of the case have been reported in English language journals and media. We provide a detailed description of the case, review the main challenges of preparing and applying AEDs for persons with dementia and briefly assess the adequacy of the current oversight system governing AEDs.

\section{INTRODUCTION}

The practice of relying on advance euthanasia directives (AEDs) to authorise euthanasia and assisted suicide (EAS) is controversial, even among euthanasia proponents. ${ }^{1-3}$ Several EAS cases in the Netherlands involving AEDs have been publicised. ${ }^{4}$ In one case, the physician of a patient with dementia surreptitiously placed a sedative into the patient's apple sauce prior to his euthanasia, ${ }^{5}$ although this detail was apparently not reported to the euthanasia review committee. ${ }^{6}$ This case led to a critical opinion piece signed by 33 Dutch physicians, ${ }^{7}$ a newspaper advertisement opposing AED authorisation of EAS for dementia signed by 220 Dutch physicians ${ }^{8}$ and an associated fund-raising campaign involving 450 Dutch physicians. ${ }^{9}$

In this paper, we focus on a 2016 case of euthanasia for an elderly patient with Alzheimer's disease that illustrates the central ethical challenges in preparing and applying AEDs. Although it is not the first instance of AED-based euthanasia in the Netherlands, this case is notable because a Dutch review committee found that the physician performing euthanasia failed to follow the Dutch statutory EAS criteria (box 1), and for the first time since the Dutch legislation was enacted in 2002, public prosecutors have opened a criminal investigation into the physician's actions. ${ }^{10}$ Additionally, the key controversial details of the case are included in the official case report, rather than solely in media reports. Thus far, only brief descriptions of this case have been reported in academic and news media. Given its importance, the case deserves a much fuller treatment than it has received. Our goals in this paper are to provide a detailed description of the case, review the major ethical issues it raises and briefly discuss potential weaknesses in the existing regulation of AEDs.

\section{CASE PRESENTATION}

Mrs A (a pseudonym) was a woman in her 70s who began developing symptoms of memory loss 9 years before her death. Four years before her death, she was diagnosed with Alzheimer's disease. ${ }^{\text {i }}$

Mrs A had previously observed a family member deteriorate from dementia, and she 'always said she didn't want to go through (that) herself. She was very fearful of developing dementia'. After her diagnosis, she repeatedly expressed to her family and physician that she 'did not want to be placed in a nursing home, and that if this were to happen, she would want euthanasia'.

Shortly after receiving the Alzheimer's diagnosis, Mrs A wrote an AED. The document included the following clause:

I want to make use of the legal right to undergo voluntary euthanasia when I am still at all mentally competent and am no longer able to live at home with my husband. I absolutely do not want to be placed in an institution for elderly dementia patients. I want to take a dignified farewell from my precious loved ones... Trusting that at the time when the quality of my life has ended up in the above-described situation, I would like to undergo voluntary euthanasia.

About 1 year before Mrs A's death ( $>3$ years after diagnosis of Alzheimer's disease), she revised her directive. This version was very similar to the first version, but included the following two sentences:

I want to make use of the legal right to undergo euthanasia whenever I think the time is right for this... Trusting that at the time when the quality of my life has become so poor, I would like for my request for euthanasia to be honored.

The case report notes that the patient's family physician believed the patient was competent when she prepared both the original and revised directives. Later that year, the patient regularly said she wanted to die but often added, 'But not yet'. Months later, during a visit to the family doctor, Mrs A was 'not concerned with euthanasia'. When her husband reminded her that she might need to go to a nursing home soon, she said she might want EAS ('OK,

\footnotetext{
i All quotations in this section come from the review committee report of the case. ${ }^{29}$ The report was professionally translated using the medical translation service at the National Institutes of Health Library and supplemented when needed by consultation with Dutch-speaking academics.
} 
Box 1 Brief background on euthanasia and physicianassisted suicide practice and regulation in the Netherlands

The practice of legally protected euthanasia or assisted suicide (EAS) has been in existence for several decades in the Netherlands, although formal legislation was not enacted until 2002 with the Termination of Life on Request and Assisted Suicide (Review Procedures) Act. ${ }^{27}$ This legislation provides medical 'due care' criteria that must be met for euthanasia by a physician to be permitted. ${ }^{27}$ These criteria require that a physician performing EAS must ${ }^{11}$ :

A. be satisfied that the patient's request is voluntary and well-considered;

B. be satisfied that the patient's suffering is unbearable, with no prospect of improvement;

C. have informed the patient about his situation and his prognosis;

D. have come to the conclusion, together with the patient, that there is no reasonable alternative in the patient's situation;

E. have consulted at least one other, independent physician, who must see the patient and give a written opinion on whether the due care criteria set out in (A) to (D) have been fulfilled;

F. exercise due medical care and attention in terminating the patient's life or assisting in his suicide.

Section 2(2) of the law allows EAS based on an advance directive, and the euthanasia review committee's Code of Practice explains how: 'a patient aged 16 or over who is decisionally competent in the matter may draw up an advance directive setting out a request for euthanasia. If at some point the patient is no longer capable of expressing his will, the physician may accept the advance directive as a request pursuant to the (Dutch euthanasia) Act. The advance directive thus has the same status as an oral request for euthanasia'..11 (p23) When the advance directive replaces an oral request, the other due care criteria apply 'to the greatest extent possible'.(p23) The physician can judge the advance directive euthanasia request based on the content of the advance directive, previous conversations with the patient and conversations with the patient's family or representative. Physicians are also expected to 'be alert to any behavior and utterances that may indicate resistance or objections to termination of life. If this is the case, euthanasia may not be performed'. ${ }^{11}$ (p24)

Under the law, the Dutch regional euthanasia review committees (Regionale Toetsingscommissies Euthanasie (RTE)) review all EAS reports to determine whether the notifying physicians (physicians who performed EAS) acted in accordance with the statutory due care criteria laid out in the EAS legislation. The RTE publishes a selection of their reports to provide 'transparency and auditability' of EAS practice and 'to make clear what options the law gives physicians..$^{28}(\mathrm{p} 4)$

maybe then'). Yet when the EAS procedure was described to her, 'the patient then thought again that that was going too far'.

Mrs A's husband cared for her at home until the last 6 months of her life, at which point she began to attend day care. Seven weeks before her death, Mrs A was admitted full-time into a nursing home because her husband 'was finally no longer able to care for her at home'. When Mrs A arrived at the facility, her 'husband asked the (nursing home geriatrician) to... (implement) euthanasia based on the written advance directive...' The geriatrician decided to give Mrs A 1 month 'to get used to the new (nursing home) environment' and then to 'evaluate whether the patient was suffering'. She observed the patient frequently and 'spoke to her for a long time'.

While Mrs A lived in the nursing home, things generally went well for her in the mornings. During the afternoons, however, she 'exhibited signs of restlessness, and she appeared deeply unhappy'. The case report states that Mrs A 'was continuously occupied with directing and instructing her fellow residents as though they were children' (she had worked with children in the past). If the caregivers intervened in conflicts between Mrs A and other nursing home residents, Mrs A sometimes 'hit, kicked, scratched and bit' the caregivers. She regularly told her caregivers that she wanted to die. But when she was asked whether she wanted to die, several times she answered, 'But not just now, it's not so bad yet!' Mrs A's geriatrician thought that her inconsistent wishes reflected a loss of insight into her illness.

Mrs A also 'missed her husband and wandered around looking for him until late at night'. Mrs A felt better during her husband's daily visits, but she became 'restless and sad' when he left the nursing home. Based on these findings, the geriatrician believed that Mrs A was suffering unbearably for most of the day, and that euthanasia was appropriate given her advance directive.

As part of the euthanasia procedures, the geriatrician consulted with two physicians trained to evaluate patients requesting euthanasia. The first doctor, a psychiatrist, 'concluded that (Mrs A) was mentally incompetent... (and) the patient was suffering hopelessly and intolerably'. The psychiatrist thought that psychosocial interventions and attempts to help Mrs A acclimate to the nursing home were fruitless. She concluded that the Dutch statutory requirements for euthanasia were met. The second physician was at first 'not convinced of the intolerable nature of (Mrs. A's) suffering' because she appeared cheerful when he visited her. But after watching and reading transcripts of video recordings (especially of 'heartbreaking scenes when the patient's husband left her in the nursing home after his visit'), he concluded that Mrs A was suffering intolerably and hopelessly, and that the legal criteria were met.

On the morning of the euthanasia, Mrs A's husband, her child and her child's partner were present in Mrs A's nursing home bedroom. The geriatrician placed a sedative in Mrs A's coffee without informing her because she 'would have asked questions about (the sedative) and refused to take it', and because 'the physician wanted to prevent a struggle during the euthanasia'. About 45 min later, the geriatrician 'concluded that the (sedative) dose had been insufficient' and gave Mrs A additional sedative subcutaneously. After she was in a state of reduced consciousness, a paramedic inserted an infusion line. The geriatrician decided not to administer lidocaine before injecting thiopental because Mrs A 'had scarcely responded to pain stimuli' during the placement of the infusion line. But to the geriatrician's surprise, Mrs A 'tried to get up during the injection of the thiopental. Then the patient's family helped to hold the patient in place, and the physician quickly administered the rest of the thiopental'. At that point, the geriatrician administered a final dose of a neuromuscular blocker to complete the euthanasia.

The geriatrician later reported to the euthanasia review committee that 'the patient was not mentally competent, so her utterance at (the moment of euthanasia) was not relevant in the physician's opinion. Even if the patient had said at that moment: "I don't want to die", the physician would have continued with the termination of life. The physician 'emphasised that she wanted to be fully transparent regarding the manner in which the termination of life proceeded, since in 
Box 2 Euthanasia review committee judgement of Mrs A's case $^{29}$

The euthanasia review committee (RTE) evaluating Mrs A's case found that the physician could have reasonably concluded that Mrs A was suffering hopelessly and unbearably, even though she had periods of time without suffering. The committee also concluded that there were no reasonable alternatives, that the physician appropriately consulted independent doctors and that Mrs A had been adequately informed before she was incompetent. But the committee said the physician failed to exercise due care in applying criterion a (voluntary and well-considered request) and criterion $f$ (due medical care).

The RTE did not question Mrs A's competence at the time of writing her advance directive requests (4 years and 1 year before her death-all after the diagnosis of Alzheimer's disease). The RTE stated that ' $(t)$ he Committee sees no reason to doubt' the family physician's assertion that the patient was competent at both time points. The RTE was also satisfied that ' $(\mathrm{t})$ he patient's family doctor and the treating geriatrician explained fully to the patient, while she was still mentally competent, the situation she was in and her prospects'.

But the RTE took issue with the euthanasia performing physician's interpretation of the AED. The RTE observed that the advance directive 'can be read in different ways. From the wording of these clauses ('when I consider that the time is right for me' and 'on my request') and also viewed against the background of the wording of the first dementia clause ('while I am still somewhat mentally competent') it can be deduced that the patient, when preparing them, assumed that she herself could and would request euthanasia at the time she chose'. Although the RTE conceded that the AED could also be read more broadly, the committee declared that because 'the current matter involves a question of life and death and the termination of life is irreversible, ... it would be best to stay on the safe side and maintain the more restrictive reading of the dementia clause'.

Additionally, the committee felt that the physician 'crossed a line' in her administration of the euthanasia drugs. The surreptitious administration of a sedative in Mrs A's coffee indicated that the physician 'wanted to take away from (Mrs A) the opportunity to physically resist the insertion of the infusion line and administration of the euthanasia'. The Committee wrote that the physician should have considered whether Mrs A's reaction to the thiopental injection was 'a significant sign that (she) did not want to have an infusion and an injection administered to her'. The committee argued, 'The physician... should not have continued with the implementation during which the patient had to be restrained... During the implementation of the (euthanasia), any duress, even the appearance of duress, must be prevented at any cost'. The committee concluded that the euthanasia was not performed in a medically careful manner.

the future, euthanasia might occur more frequently in incompetent patients.'

According to Mrs A's family physician, Mr A had been 'afraid that the euthanasia would not take place', but thought that the euthanasia 'had occurred calmly'. Mr A was 'eventually happy that (Mrs A) had received euthanasia, this is what (she) had always wanted...'

The Dutch euthanasia review committee (RTE) found that Mrs A's case failed to meet the due care criteria of a voluntary and well-considered request and due medical care (box 2).

\section{ANALYSIS}

Mrs A's case provides insights into the ethical challenges AEDs present, due to difficulties in both AED preparation and AED application.

\section{Preparing advance euthanasia directives}

Preparing an AED is a more complicated task than making an immediate request for EAS. Besides determining whether she wants to die in this manner, the patient must project herself into the future to weigh the pros and cons of uncertain events. The patient must also specify a 'trigger' point for implementation. Was Mrs A capable of this task, and did she in fact perform that task satisfactorily?

First, it is not clear that Mrs A possessed adequate decision-making capacity when she wrote and revised her AED. The RTE endorses a functional capacity framework in which someone is deemed capable if he is 'able to understand relevant information about his situation and prognosis, consider any alternatives and assess the implications of his decision'. ${ }^{11}$ This is similar to the framework developed by Grisso and Appelbaum, ${ }^{12}$ which is widely used in the US and other jurisdictions. Studies using the functional capacity framework show that most patients with Alzheimer's disease are incapable of making treatment and research decisions, ${ }^{13}$ including simple decisions regarding medication for Alzheimer's disease. ${ }^{14}$ Even mild cognitive impairment (a condition that precedes Alzheimer's disease by 3-4 years ${ }^{15}$ ) can cause significant impairment in decision making, ${ }_{17}$ with $40 \%$ of patients lacking capacity for research decisions. ${ }^{17}$ Mrs A's symptoms had begun 9 years prior to her death; she was formally diagnosed with Alzheimer's disease 5 years later. Thus, even at the time of diagnosis, she would have been at high risk of incapacity.

Second, there is evidence that Mrs A's impaired abilities contributed to the use of confusing language in her AED. Mrs A's first AED, written shortly after her Alzheimer's diagnosis, contained conflicting statements. She said she wanted EAS "when I am still at all mentally competent" (seeming to imply a desire to make the decision herself sometime in the future), but also stated, "Trusting that at the time when the quality of my life has ended up in the above-described situation, I would like to undergo voluntary euthanasia" (seeming to imply a directive based on quality of life). She revised her AED 3 years after her Alzheimer's diagnosis, at a time when her abilities would have deteriorated even further. The new AED referred to "whenever I think the time is right" and "when the quality of my life has become so poor, I would like for my request for euthanasia to be honored". With this change, did she intend to remove the ambiguity in the first version and replace the previous instructional directive with a request to receive EAS only at her contemporaneous request? It is puzzling that her family physician was apparently not able to clarify to the RTE the patient's intent, despite her belief that Mrs A was competent to change her AED.

Third, there is little evidence that Mrs A actually weighed the relevant pros and cons of requesting future EAS. Mrs A mentions that she saw her mother decline from dementia and did not want to experience a similar fate. Although this is certainly one important form of knowing about dementia, there is no evidence that she incorporated other relevant information into her request, perhaps because she was too impaired (especially 3 years after her diagnosis) to appreciate other relevant information. It is not easy to predict the experience of mental decline or its future effects on one's quality of life. Personality changes due to dementia will vary, and a 
person may experience moments of lucidity, showing her 'old self', even with severe dementia. ${ }^{3}$ Anticipating the burden of future health decline is complicated because people underestimate their ability to adjust to their health states after developing disease or disability. ${ }^{18}$ An AED written when one is no longer able to imagine and incorporate how one might cope with a given condition has limited validity. Additionally, this lack of information may be reinforced by prejudicial attitudes towards disease and disability, with images of incontinence, confusion, agitation and loss of mobility, rather than a more balanced picture incorporating the pleasures and enjoyment that many patients experience. ${ }^{1} 19$

Two features of the Dutch EAS system work against optimising the validity of AEDs. First, physicians and the RTE accept a low threshold of decisional capacity for preparing AEDs. The RTE's Code of Practice states that in early dementia, "the patient generally...is decisionally competent in relation to his request for euthanasia". ${ }^{11}$ This apparent presumption of capacity in early AD (and in the case of Mrs A's second AED, a much more advanced state) is incompatible with existing data on Alzheimer's disease and decisional capacity. Dutch physicians, as in this case, tend simply to assert their capacity judgement without detailed justification, even when EAS is requested by persons at elevated risk of incapacity. ${ }^{20}$

The second feature of the Dutch system that may promote suboptimal preparation of AEDs in patients with dementia is the law's failure to require an independent consultation for patients preparing AEDs, as it does for physicians implementing AEDs and physicians assessing requests for contemporaneous EAS. But this presents a paradox: given that the patient's desire for EAS is expressed at the time of writing the AED, rather than when EAS occurs, a particularly controversial form of EAS request by a cognitively vulnerable patient receives less scrutiny than does a contemporaneous request by a cognitively intact person.

\section{Applying advance euthanasia directives}

Mrs A's case also illustrates the challenges in applying AEDs to patients with dementia. Some of these challenges are related to flaws in the preparation process. As mentioned earlier, Mrs A's AED contained notable ambiguities, and it was unclear whether she wanted the AED document alone to satisfy a euthanasia request. Furthermore, interpreting AED activation criteria can be difficult even when the preparer supplies consistent directions. Activation criteria that are too broad will place the burden of interpretation and decision making on the family and physicians. ${ }^{2}$ On the other hand, overly specific criteria may fail to encompass the full range of symptoms the patient seeks to avoid.

Mrs A's case also highlights a more fundamental challenge to applying AEDs: the 'then-self versus now-self' problem. ${ }^{21}$ As cognitive abilities of patients with dementia decline, they typically forget about their AEDs and the requests the documents contain. What matters to them as patients with later-stage dementia will ordinarily be different than what mattered to them when they prepared their AEDs. As a result, the decision to perform euthanasia can be contrary to their interests and preferences as patients with dementia. Some writers, such as Ronald Dworkin, contend that the competent person's interest in securing a death consistent with her personal values should take priority over her later welfare interests as an incompetent patient. $^{22-24}$ Others, including us, are critical of this view and favour limiting the authority of advance directives when they conflict with the incompetent patient's current welfare and wishes. $^{2425}$

The 'then-self versus now-self' problem is a long-standing philosophical debate that we cannot resolve in this paper. However, we note that existing medical and legal norms do assign considerable weight to a person's current preferences and welfare interests, rather than giving absolute authority to an advance directive in making life-or-death decisions. Dworkin himself recognised a limit on the authority of advance directives (eg, in the case of advance refusals of pain-relieving treatments). ${ }^{22}{ }^{25}$ Moreover, the RTE Code of Practice stipulates (box 1) that the physician may not follow an AED if the incapacitated patient shows signs of resisting or objecting to EAS, and the statute's unbearable suffering requirement still applies to these patients. ${ }^{11}$ And, as noted above, many Dutch physicians, even those who are advocates of EAS (including at least one who works with the End of Life Clinic ${ }^{\mathrm{ii}}$ ), strongly oppose AED authorisations of EAS. ${ }^{8}$ In many healthcare settings, resolving a conflict between an advance directive and contemporaneous patient interests and preferences would lead to a more formal evaluation process in which multiple individuals, including ethicists, institutional officials and sometimes legal authorities, would decide how best to proceed. Determining the relative weight of a patient's advance directive request and that patient's current welfare interests and preferences is a complex task, one that we believe should not be left to an individual physician's judgement.

The geriatrician in Mrs A's case prioritised Mrs A's advance euthanasia directive over her later assertions that she was not ready to die. The geriatrician also regarded the patient's previous euthanasia request as an adequate basis for using deception and coercion in carrying out the AED request. Furthermore, according to the geriatrician, Mrs A's conflicting statements about euthanasia were 'not relevant' because they reflected her lack of awareness and insight. It is concerning that the Dutch system of retrospective review made it possible for the geriatrician to implement her own solution to a longstanding philosophical dispute with no more input than the non-binding opinions of consultants (who were at any rate unaware of her use of deception and coercion in Mrs A's euthanasia).

A final question is whether Mrs A was experiencing intolerable suffering as the Dutch EAS law requires. The physicians involved in Mrs A's case believed that she was, and the RTE affirmed this finding, noting that 'to reach this conclusion it is not necessary for the patient to suffer intolerably every minute of the day'. This declaration is an insufficient response to the intolerable suffering question, for it speaks only to the evidence that is not needed to support such a finding. The RTE should have explained in greater detail why the evidence in this case was sufficient to establish the patient's intolerable suffering. Although it is true that Mrs A suffered daily periods of distress, she also had daily periods in which she appeared happy and content. Every human life has its ups and downs. When do the burdens of life with dementia become sufficiently heavy to justify a finding of unbearable and irremediable suffering? At minimum, Mrs A's case points to a need for a more thorough examination of this question.

\footnotetext{
ii The End of Life Clinic is a mobile euthanasia clinic in the Netherlands. It was founded by a euthanasia advocacy organisation, and its main purpose is to provide euthanasia to eligible patients who were denied EAS by their primary physicians. ${ }^{26}$
} 


\section{CONCLUSION}

Between 2002, when the Dutch law was passed, and 2016, there were 49287 reported cases of EAS in the Netherlands. The RTE found that 89 of those cases violated the law's 'due care criteria'. ${ }^{26}$ Mrs A's case is the first to trigger a criminal investigation. It is not surprising that the case involved EAS of a patient with dementia, as this is a form of legally permitted EAS that has engendered significant disagreement, both inside and outside of the Netherlands. ${ }^{1-3}$

Mrs A's case demonstrates the myriad ethical concerns raised by AEDs. The Dutch system risks imputing more abilities to patients with dementia than they may possess. The RTE appears to allow a low threshold of capacity and degree of understanding for patients creating AEDs. Disturbingly, there is no independent consultation process evaluating the (often vulnerable) patient's preparation of an AED. These features of the system likely resulted in the failure to ensure Mrs A's competence, understanding or clear expression of her desires in preparing her AED. Not surprisingly, this eventually led to difficulties in applying her AED.

The failure to provide adequate protection to a vulnerable patient was exacerbated by the failure to respect her contemporaneous interests and statements. By privileging the AED as the expression of Mrs A's 'real self'-a judgement that itself was dubious in light of her questionable capacity and understanding when she made the AED—physicians failed to protect her a second time when they disregarded her contemporaneous statements and actions.

Finally, Mrs A's case reflects weaknesses of the Dutch EAS retrospective review system. The retrospective nature of the review system allows physicians to act on personal judgements about philosophically controversial dilemmas, rather than requiring a more formal and thorough evaluation. (Although consultation is a requirement, agreement is not necessary and consultants are not present when EAS is implemented.) Furthermore, any abuses or errors will come to light only if physicians fully report their actions. Improper actions by physicians who are not as forthcoming as Mrs A's physician will not be detected, as happened in the case described in the Introduction. ${ }^{26 i i i}$

Although Mrs A's case is unusual in that it has led to a criminal investigation, the challenges AEDs present for patients with dementia are hardly unique to her case. The case came to the attention of the RTE only because the geriatrician was interested in setting a precedent and therefore faithfully conveyed the details of her reasoning and actions. The geriatrician believed that Mrs A's 'utterance at (the moment of euthanasia) was not relevant' and indeed would have proceeded even if Mrs A had said "I don't want to die". The physician's open defence of a controversial normative decision to end a life of a patient with dementia could be an anomaly. But it could also reflect an evolution in how persons with dementia are perceived. The Dutch authorities conducting the criminal investigation could determine the future direction of AEDs for persons with dementia.

Acknowledgements The authors thank Marie Nicolini and Frank Miller for helpful comments on an earlier draft, and Trudo Lemmens and Dr Nicolini for help in evaluating Dutch-to-English translations of key texts.

Contributors All three authors have contributed to qualify for authorship: substantial contributions to the conception of the work; or the acquisition, analysis or interpretation of data for the work; drafting the work or revising it critically for important intellectual content; final approval of the version to be published;

\footnotetext{
iii We thank two anonymous reviewers for their constructive comments
} that helped us to clarify these points. agreement to be accountable for all aspects of the work in ensuring that questions related to the accuracy or integrity of any part of the work are appropriately investigated and resolved.

Funding Supported in part by the Intramural Research Program of the NIH Clinical Center. RD was a Visiting Scholar in the Department of Bioethics during the period of writing this paper.

Disclaimer The opinions expressed in this article are the authors' and do not represent the views or policies of the $\mathrm{NIH}$, Department of Health and Human Services or any other part of the USA Government.

Competing interests None declared.

Patient consent Not required.

Provenance and peer review Not commissioned; externally peer reviewed. Data sharing statement All of the data used in this study are publicly available. Author note All authors meet the ICMJE 2013 criteria for authorship. (C) Article author(s) (or their employer(s) unless otherwise stated in the text of the article) 2019. All rights reserved. No commercial use is permitted unless otherwise expressly granted.

\section{REFERENCES}

1 Chabot B. Verontrustende cultuuromslag rond de zelfgekozen dood. NRC. 2017, https://www.nrc.nl/nieuws/2017/06/16/de-euthanasiegeest-is-uit-de-fles-11123806a1563406 (accessed 10 Aug 2017).

2 van Delden JJ. The unfeasibility of requests for euthanasia in advance directives. J Med Ethics 2004;30:447-51

3 Menzel PT, Steinbock B, Directives A. Dementia, and Physician-Assisted Death. J Law Med Ethics 2013;41:484-500.

4 Hertogh C, Slaets J, Zuidema S, et al. Nee, niet heimelijk euthanasie plegen. NRC. 2017, https://www.nrc.nl/nieuws/2017/02/14/nee-niet-heimelijk-euthanasie-plegen6698665-a1546043 (accessed 10 Aug 2017).

5 Effting M. En opeens was het moment voorbij. Volkskrant. 2017, https://www. volkskrant.nl/wetenschap/en-opeens-was-het-moment-voorbij a4444440/ (accessed 19 Dec 2017)

6 Regional Euthanasia Review Committees, The Hague, the Netherlands. Oordeel 201638. 2017, https://www.euthanasiecommissie.nl/uitspraken/publicaties/oordelen/2016 uitzichtloos-en-ondraaglijk/oordeel-2016-38 (accessed 21 Dec 2017).

7 Chabot B. Dood nooit weerloze die het niet beseft. Volkskrant. 2017, https://www. volkskrant.nl/opinie/dood-nooit-weerloze-die-het-niet-beseft a4451117/ (accessed 20 Aug 2017).

8 van Steenbergen E, Ritzen G. Artsen: dementerenden kunnen te eenvoudig euthanasie krijgen. NRC. 2017, https://www.nrc.nl/nieuws/2017/02/09/artsen-tegeneuthanaseren-van-dementen-op-basis-van-wilsverklaring-a1545325 (accessed 19 Dec 2017).

9 Planting A. PERSBERICHT - Artsen schenken aan proeftuin. Tao of Care 2017, http:// tao-of-care.nl/persbericht-artsen-schenken-aan-proeftuin/ (accessed 19 Dec 2017).

10 Public prosecutor investigates euthanasia of woman with dementia. DutchNews. nl. 2017, https://www.dutchnews.nl/news/archives/2017/09/public-prosecutorinvestigates-euthanasia-of-woman-with-dementia/ (accessed 8 Oct 2017).

11 Regional Euthanasia Review Committees, The Hague, the Netherlands. Code of Practice. 2015, https://www.euthanasiecommissie.nl/de-toetsingscommissies/uitspraken/brochures/ brochures/code-of-practice/1/code-of-practice (accessed 20 Jul 2017).

12 Appelbaum PS. Assessment of Patients' Competence to Consent to Treatment. N Engl J Med 2007;357:1834-40.

$13 \mathrm{Kim}$ SY. The ethics of informed consent in Alzheimer disease research. Nat Rev Neurol 2011;7:410-4

14 Karlawish JH, Casarett DJ, James BD, et al. The ability of persons with Alzheimer disease (AD) to make a decision about taking an AD treatment. Neurology 2005:64(9):1514-9.

15 Handels RL, Xu W, Rizzuto D, et al. Natural progression model of cognition and physical functioning among people with mild cognitive impairment and Alzheimer's disease. J Alzheimers Dis 2013:37(2):357-65.

16 Okonkwo O, Griffith HR, Belue K, et al. Medical decision-making capacity in patients with mild cognitive impairment. Neurology 2007;69:1528-35.

17 Jefferson AL, Lambe S, Moser DJ, et al. Decisional capacity for research participation in individuals with mild cognitive impairment. J Am Geriatr Soc 2008(7);56:1236-43.

18 Menzel P, Dolan P, Richardson J, et al. The role of adaptation to disability and disease in health state valuation: a preliminary normative analysis. Soc Sci Med 2002;55:2149-58.

19 Asch A. Recognizing death while affirming life: can end of life reform uphold a disabled person's interest in continued life? Hastings Cent Rep 2005;35:s31-s36.

20 Doernberg SN, Peteet JR, Kim SY. Capacity evaluations of psychiatric patients requesting assisted death in the Netherlands. Psychosomatics 2016;57:556-65.

21 Menzel PT, Chandler-Cramer MC. Advance directives, dementia, and withholding food and water by mouth. Hastings Cent Rep 2014:44:23-37.

22 Dworkin R. Life's dominion: an argument about abortion, euthanasia, and individual freedom. Vintage Books. 1993. 
23 Buchanan AE, Brock DW. Deciding for Others: the Ethics of Surrogate Decision Making. Cambridge: Cambridge University Press, 1989.

24 Dresser R. On legalizing physician-assisted death for dementia. Hastings Cent Rep 2017:47:5-6.

25 Dresser R. Dworkin on dementia. Elegant theory, questionable policy. Hastings Cent Rep 1995;25(6):32-8.

26 Miller DG, Kim SYH. Euthanasia and physician-assisted suicide not meeting due care criteria in the Netherlands: a qualitative review of review committee judgements. BMJ Open 2017;7(10):e017628.
27 Griffiths J, Weyers H, Adams M. Euthanasia and law in Europe. 2nd edn. Portland: OR: Hart Publishing, 2008.

28 Regional Euthanasia Review Committees, The Hague, the Netherlands. Annual Report. 2013, https://www.euthanasiecommissie.nl/uitspraken/jaarverslagen/2013/nl-en-dufr/nl-en-du-fr/jaarverslag-2013 (accessed 19 Sep 2016).

29 Regional Euthanasia Review Committees, The Hague, the Netherlands. Oordeel 2016-85. 2017 https://www.euthanasiecommissie.n//uitspraken/publicaties/oordelen/2016/nietgehandeld-overeenkomstig-de-zorgvuldigheidseisen/oordeel-2016-85 (accessed 21 Jul 2017). 